\title{
Reduced Competitive Repopulation Capacity of Multipotential Hematopoietic Stem Cells in the Bone Marrow of Friend Virus-infected Fv2-resistant Mice
}

\author{
MICHAEL W. EPPERLY ${ }^{1}$, XICHEN ZHANG $^{1}$, RENEE FISHER $^{1}$, WEN HOU ${ }^{1}$, \\ DARCY FRANICOLA ${ }^{1}$, DONNA SHIELDS ${ }^{1}$, MICHAEL QUICKEL ${ }^{2,3}$, \\ PAMELA HANKEY-GIBLIN ${ }^{2}$, HONG WANG ${ }^{1}$ and JOEL S. GREENBERGER ${ }^{1}$ \\ ${ }^{1}$ Department of Radiation Oncology, University of Pittsburgh Cancer Institute, Pittsburgh, PA, U.S.A.; \\ ${ }^{2}$ Department of Veterinary and Biomedical Science, Center for Molecular Immunology \\ and Infectious Disease, Penn State University, University Park, PA, U.S.A.; \\ ${ }^{3}$ Clinical and Translational Science Institute, Penn State University College of Medicine, Hershey, PA, U.S.A.
}

\begin{abstract}
Background/Aim: The polycythemia form of Friend leukemia virus (FVP) causes splenomegaly and lethal erythroleukemia in $F v-2^{s}$-susceptible mouse strains. We sought to determine whether the hematopoietic stem cell (HSC) pool was expanded in Fv-2 ${ }^{r}$-resistant mice. Materials and Methods: The 120-day bone marrow transplantation competitive repopulation assay was used to determine whether FVP-infected $F v$-2 $2^{r}$ C57BL/6 mice demonstrated expansion of the HSC pool compared to the pool of committed hematopoietic progenitor cells in the same marrow assayed in vitro. Results: There was a significant expansion of committed hematopoietic progenitors observed in virus-infected $F v-2^{s} F V B$ mice, but not $F v-2^{r} C 57 B L / 6$ mice. Furthermore, $F v-2^{r}$ mice showed no detectable expansion of either committed hematopoietic progenitor cells or the multipotential stem cell pool by competitive repopulation assay. Conclusion: Friend virus disease in $F v-2^{s}$ mice is associated with expansion of committed hematopoietic progenitors. Fv-2 ${ }^{r}$ mice show no expansion of either committed progenitor or pluripotential stem cell numbers.
\end{abstract}

This article is freely accessible online.

Correspondence to: Joel S. Greenberger, MD, Professor and Chairman, Department of Radiation Oncology, University of Pittsburgh Cancer Institute, UPMC Cancer Pavilion, 5150 Centre Avenue, Rm. 533, Pittsburgh, PA 15232, U.S.A. Tel: +1 4126473602, Fax: +1 4126476029, e-mail: greenbergerjs@upmc.edu

Key Words: Friend virus, hematopoietic stem cells, competitive repopulation assay.
Decades of research in the pathophysiology of erythroleukemia caused by the Friend virus led to the hypothesis that mouse strains susceptible to leukemia by expression of the erythropoietin receptor-linked $F v$-2 locus (1), as well as those mice resistant to erythroleukemia $\left(\mathrm{Fv}-2^{\mathrm{r}}\right)$, demonstrated expansion of the hematopoietic stem cell (HSC) pool (2). Production of erythroid leukemia by Friend virus has been shown to be dependent upon interaction of the Friend virus with the $F v$-2 locus hematopoietic stem cells in the mouse model (1). The $F v$ 2 susceptibility locus has been shown to encode a truncated form of the Stk receptor tyrosine kinase, which interacts with the erythropoietin receptor and stimulates expansion of the erythroleukemia progenitor cell population (1). Mice susceptible to Friend virus-induced erythroblastosis express both full-length Stk and the Nterminally truncated, short form-Stk, whereas resistant alleles lack the internal promoter necessary for Sf-Stk expression (1). A product of the Friend spleen focus forming virus (SFFV) env gene, glycoprotein gp55, forms disulfide bonds with Sf-Stk to stabilize it at the membrane and promote its constitutive activation in $\mathrm{Fv}-2^{\mathrm{s}}$ mice (23). Though $\mathrm{Fv} 2^{\mathrm{r}}$ mice fail to develop Friend virus-induced polycythemia, gp55 remains capable of promoting constitutive activation of Jak2 and Stat5 (24). Additionally, SFFV infection of Fv2r mice has been demonstrated to increase the self-renewal capacity of bone marrow hematopoietic stem cells (2) and long-term marrow cultures derived from these same mice produce hematopoietic progenitor cells for significantly extended durations $(3,4)$. The data suggested that gp55 or a different genetic component of the Friend virus might facilitate expansion of normal HSCs in $\mathrm{Fv}-2^{\mathrm{r}}$ mouse marrow. 
In the present study, we quantified the possible expansion of Friend virus-infected $\mathrm{Fv}_{\mathrm{V}} 2^{\mathrm{r}}$ bone marrow from C57BL/6 mice using the more rigorous 120-day competitive repopulation assay (15). We mixed virus-infected marrow in varying ratios with uninfected marrow of opposite gender mice and transplanted these mixtures into lethally-irradiated recipients to determine whether the Friend virus had expanded the stem cell pool. We compared the results with in vitro assays for numbers of committed hematopoietic progenitors from Friend virus-infected $\mathrm{Fv}-2^{\mathrm{r}} \mathrm{C} 57 \mathrm{BL} / 6$ and $\mathrm{Fv}_{\mathrm{V}} \mathrm{2}^{\mathrm{s}}$, erythroleukemic FVB mice. We further tested the hypothesis that any Friend SFFV effect on the expansion capacity of hematopoietic progenitor cells was mediated through abrogation of the negative regulator transforming growth factor-beta $(\mathrm{TGF}-\beta)$ signaling. The results demonstrate no detectable expansion of committed progenitors or HSCs in Friend virus-infected $\mathrm{Fv}-2^{\mathrm{r}}$ mice and suggest that marrow stem cell expansion cannot be separated from erythroleukemogenesis by Friend virus.

\section{Materials and Methods}

Mice. The Friend virus, erythroleukemia-sensitive $\left(\mathrm{Fv}-2^{\mathrm{s}}\right) \mathrm{FVB}$ and Friend virus-resistant $\left(\mathrm{Fv}^{2} 2^{\mathrm{r}}\right) \mathrm{C} 57 \mathrm{BL} / 6$ mice were obtained from Taconic Biosciences (Hudson, NY, USA) and housed four per cage, fed standard laboratory chow and deionized water, according to Institutional IACUC protocols. Both male and female mice were obtained and colonies maintained under identical conditions.

Virus preparation. The polycythemic variant of Friend virus (FVP) was generated form FP63 producer cells (a gift from A. Berstein, University of Toronto, Toronto, Canada). Cells were cultured in alpha-MEM, $10 \%$ FBS and $10 \mu \mathrm{g} / \mathrm{ml}$ ciprofloxacin until $90 \%$ confluent at which point medium was replaced. Viral supernatant was collected after an additional 24 hours of culture, pooled and prepared as single-use aliquots. BALB/c mice were injected retroorbitally with $100 \mu \mathrm{l} \mathrm{FVP} \mathrm{to} \mathrm{verify} \mathrm{viral} \mathrm{infectivity} \mathrm{by} \mathrm{severe}$ splenomegaly two weeks after infection.

Virus injections. Adult 6- to 8-week-old male and female mice of both mouse strains were injected intravenously with $100 \mu \mathrm{FVP}$. Fv-2s (FVB) male and female mice were observed for the development of erythroleukemia at 6-8 weeks by examination of the spleen. Mice with palpable splenomegaly were confirmed to have the Friend erythroleukemia by analysis of bone marrow and peripheral blood for leukemic erythroblasts. At this time point, bone marrow from both FVB and C57BL/6 mice was harvested and assayed for committed progenitors and multipotential hematopoietic stem cells.

In vitro colony-forming assays. $\mathrm{Fv}-2^{\mathrm{s}}$ mice were examined weekly for enlarged spleens as indications of Friend disease and, at week 4-5 when spleens were enlarged, mice of both strains were sacrificed and bone marrow harvested for in vitro colony-forming assays and for competitive repopulation assay.

For in vitro assays, fresh bone marrow from FVB, FVB (Friend virus-infected), C57BL/6 and C57BL/6 (Friend virus-infected) mice was harvested and made into single cells suspension. The bone marrow was harvested at 4-5 weeks after virus injection. This time point was chosen to coincide with the pre-morbid splenomegaly in $\mathrm{Fv}-2^{\mathrm{s}}$ (FVB) recipient mice.

Single cell suspensions of marrow were plated in varying densities ranging from $5.0 \times 10^{4}$ to $2.0 \times 10^{5}$ cells per $1 \mathrm{~cm}$ tissue culture plate in $0.8 \%$ methylcellulose-containing medium supplemented with interleukin (IL)-3, granulocyte-colony stimulating factor (G-CSF), granulocyte-macrophage colony-stimulating factor (GM-CSF), IL-6, IL-11, stem cell factor (SCF) and erythropoietin (StemCell Technologies, Vancouver, BC, Canada), according to published methods. In addition, cultures were supplemented with TGF- $\beta$ ranging from $1 \mathrm{ng} / \mathrm{ml}$ up to $1 \mathrm{mg} / \mathrm{ml}$. Cultures were incubated in $37^{\circ} \mathrm{C}$ in a high humidity incubator, $7 \%$ oxygen for 14 days. Colonies of greater than or equal to 50 cells per colony were scored at day 7 and again at day 14. Day-14 sub-populations were scored for burst forming unit erythroid (BFUe) and multi-lineage colony-forming unitgranulocyte/erythroid/megakaryocytes/macrophage (CFU-GEMM), and colony forming unit-granulocyte, macrophage (CFU-GM) according to published methods. All experiments were repeated three times from three separate virus-infected groups of mice.

In vitro assay for TGF- $\beta$ inhibition of hematopoietic stem cell colony formation. Bone marrow from adult mice was removed and single cell suspensions prepared. Cells were plated in semisolid medium containing IL-3, G-CSF, GM-CSF, IL-6, IL-11 and erythropoietin, according to published methods. Colony-forming at days 7,10 and 14 were scored separating for CFU-GM CFUGEMM and $\mathrm{BFU}_{\mathrm{e}}$, according to published methods. Total colonies were also scored at each time point. Plating densities ranged from $1 \times 10^{4}$ to $1 \times 10^{5}$ cells per $1 \mathrm{ml}$ culture volume. For TGF- $\beta$ inhibition assay, concentrations of TGF- $\beta$ ranging from $0.1 \mathrm{mg} / \mathrm{ml}$ to $1 \mu \mathrm{g} / \mathrm{ml}$ were utilized. Results were plotted as percent inhibition of colony formation by TGF- $\beta$.

Assays for intact TGF- $\beta$ signaling pathways in friend virusinfected fresh $F v-2^{r}$ and $F v-2^{s}$ marrow. Assays for each of 5 TGF$\beta$ signaling pathways were carried out, according to published methods (23). Assays for the canonical signaling pathway through: (i) SMAD3; (ii) the phospho-ERK pathway or noncanonical pathways; (iii) PI3-Kinase pathway; (iv) p38, JNK-1 pathway; and (v) the RHO-Kinase pathway were carried out, according to published methods for Western blots $(12,23)$. Western blots were carried out three times on three sets of bone marrow from the four treatment groups (virus-infected or uninfected FVB on C57BL/6 mice).

Competitive repopulation assay. Methods for the competitive repopulation assay have been described in detail (15). Briefly, donor marrow for transplant was harvested from virus-infected and control uninfected male and female C57BL/6 mice and single cell suspensions mixed in varying ratios of male to female comparing virus-infected to uninfected. Experiments consisted of virus-infected female with uninfected male, virus-infected male with uninfected female in both directions and marrow was transplanted into lethally irradiated (1,000 cGy split course) C57BL/6 female recipients. The ratio of virus-infected to -uninfected varied from 10 to 1,3 to 1,1 to 1,1 to 3 , and 1 to 10 .

Female C57BL/6 transplant recipients were injected intravenously with each mixture of donor marrow cells and 
followed for 120 days, then sacrificed and the bone marrow removed. Bone marrow was tested for the presence of the Ychromosome by polymerase chain reaction (PCR).

DNA isolation and quantitative-polymerase chain reaction. Mouse bone marrow treated with ACK Lysing Buffer (Quality Biological, Gaithersburgh, MD, USA, Cat. No: 118-156-101), then DNA was isolated using DNeasy Blood \& Tissue Kit (Qiagen, Venlo, The Netherlands, Cat. No: 69504). DNA quantitated using a spectrophotometer (Beckman Coulter, Brea, CA, USA, DU 530), then diluted to $0.05 \mu \mathrm{g} / \mu \mathrm{l}$.

For quantitative PCR, $4 \mu \mathrm{l}$ of DNA, $10 \mu \mathrm{l}$ of iTaq Universal Probes Supermix (Bio-Rad, Hercules, CA, USA, Cat. \#: 172-5134), $1 \mu \mathrm{l}$ of primer and $4 \mu \mathrm{l}$ of nuclease-free water were used.

Primers for mouse Y chromosome Uty genes were used from Applied Biosystems (Thermo Fisher Scientific, Pittsburgh, PA, USA, Cat. \#: Mm00527273_cn). Primers for inner control Tfrc genes were selected from Applied Biosystems (Cat. \#: 4458370). The thermocycler conditions were $95^{\circ} \mathrm{C}$ for $2 \mathrm{~min}, 1$ cycle then went to $95^{\circ} \mathrm{C}$ for 15 second, $59^{\circ} \mathrm{C}$ for $30 \mathrm{sec}$ for 45 cycles. QT-PCR performed on a MastercyclerRealplex ${ }^{2}$ from Eppendrof (San Diego, CA, USA). Triplicates were accepted in a 0.5 cycle threshold (CT) range. Relative quantification was achieved using the $\Delta \Delta \mathrm{Ct}$ method.

Statistical analysis. In vitro colony assays for explanted whole bone marrow cells in single cell suspension were scored at days 7 and 14 and statistical evaluations carried out according to published methods (11).

For the competitive repopulation assay, the percent of mice negative for reconstitution by $\mathrm{FV}$-infected marrow at 120 days after transplant was plotted against the number of injected male mouse cells (C57BL/6 control marrow or C57BL/6 friend virus-infected marrow) mixed with female uninfected C57BL/6 marrow in varying ratios. A single-hit model was fitted for each donor cell type and comparison between the two donor types was performed with the likelihood ratio test using the asymptotic chi-square approximation $(15,22)$. We performed this test with enhanced location dependent addressing (elDA) function in statmod package of $\mathrm{R}$ software (University of California, Berkeley, CA, USA).

\section{Results}

Friend virus-susceptible $\left(F v-2^{s}\right) \quad F v B$ mice demonstrate significant expansion of committed hematopoietic progenitor cells in bone marrow. We tested the bone marrow of both C57BL/6 and FvB virus-infected compared to uninfected mice at the time point when $\mathrm{Fv} 2^{\mathrm{S}}$ mice $(\mathrm{FVB})$ demonstrated significant splenomegaly and erythroleukemia. There was a significant difference in the number of multilineage CFUGEMM hematopoietic colony-forming cells in freshlyremoved bone marrow from $\mathrm{C} 57 \mathrm{BL} / 6$ compared to $\mathrm{FVB}$ mice. Uninfected C57BL/6 mouse marrow showed higher numbers of CFU-GEMM hematopoietic progenitor cells compared to FVB mouse marrow. These results confirm and extend mouse strain differences published previously (10). As shown in Figure 1, marrow from virus-infected FVB mice showed a significant expansion of day 7 and day 14 (Figure 1) committed multilineage colony-forming cells

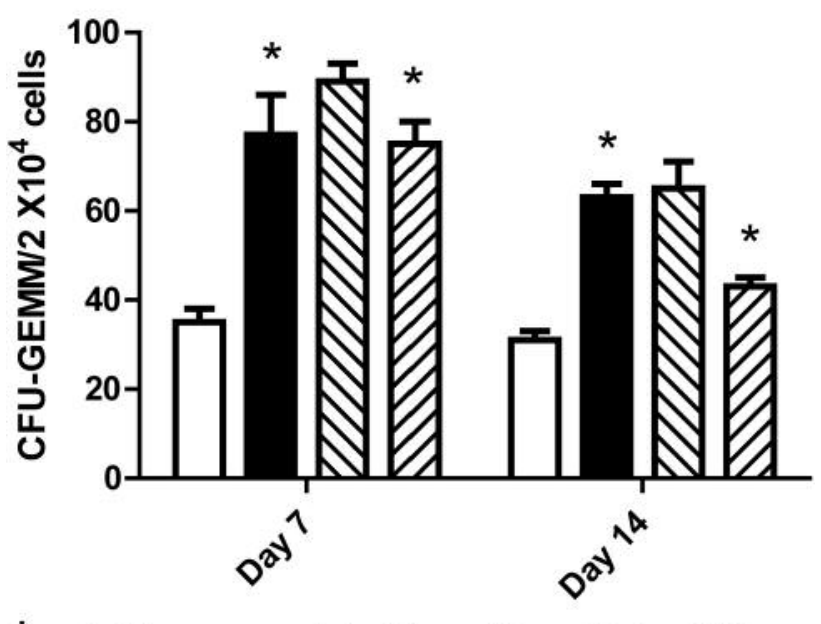

${ }^{*} p<0.05$ compared to Mice without Friend Virus

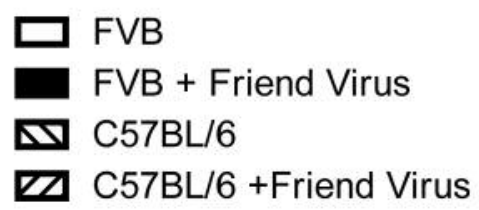

Figure 1. CFU-GEMM increases in Friend virus-infected $F v$ - $2^{s}$ and $F v$ $2^{s}$ marrow. $F V B\left(F v-2^{s}\right)$ Friend virus-infected mice have increased numbers of committed bone marrow hematopoietic progenitor cells forming CFU-GEMM colonies in vitro scored at days 7 and 14 .

compared to numbers detected in uninfected mice. In contrast, virus-infected C57BL/6 mouse marrow showed fewer multilineage colony-forming cells both in the day 7 and day 14 (Figure 1) assays. These results establish that there was no detectable expansion of numbers of multilineage hematopoietic progenitor colony-forming cells above the baseline levels in Friend virus-infected C57BL/6 mice compared to the clear virus induced expansion detected in FVB mouse marrow. Other results for separated subsets of Burst Forming Unit erythroid (BFUe) from virus-infected marrow reflected the same strain differences.

Absence of detectable expansion of true bone marrow stem cells in friend virus-infected C57BL/6 mice measured by the competitive repopulation assay. We next tested Friend virusinfected C57BL/6 mouse marrow for expansion of true multipotential hematopoietic stem cell numbers by the competitive repopulation assay. C57BL/6 male and female (donor) mice were injected with Friend virus as described in the methods. Bone marrow was isolated from male C57BL/6 donor male and female mice that had been injected with Friend virus 4 weeks previously, and from control uninfected donor male or female C57BL/6 mice. 
Table I. Friend virus infection induces expansion of committed hematopoietic progenitor cells in bone marrow of Fv-2s FvB mice as demonstrated by competitive repopulation assay.

\begin{tabular}{lccc}
\hline Male cell injected & $\begin{array}{c}\text { \#negative/\#tested (\%) } \\
\text { for male control C57BL/6 }\end{array}$ & $\begin{array}{c}\text { \#negative/\#tested (\%) for } \\
\text { male virus-infected C57BL/6 }\end{array}$ & $\begin{array}{c}p \text {-Value for comparing the groups } \\
\text { using the chi-square test }\end{array}$ \\
\hline 0 & $3 / 3(100 \%)$ & $4 / 4(100 \%)$ & 0.0024 \\
$0.1 \times 10^{6}$ & $0 / 5(0 \%)$ & $4 / 4(100 \%)$ & \\
$0.25 \times 10^{6}$ & $0 / 5(0 \%)$ & $2 / 3(66 \%)$ \\
$0.5 \times 10^{6}$ & $0 / 4(0 \%)$ & $0 / 4(0 \%)$ \\
$0.75 \times 10^{6}$ & $0 / 3(0 \%)$ & $0 / 1(0 \%)$ \\
$0.9 \times 10^{6}$ & $0 / 4(0 \%)$ & $0 / 4(0 \%)$ \\
$1.0 \times 10^{6}$ & $0 / 2(0 \%)$ & $0 / 3(0 \%)$ & \\
\hline
\end{tabular}

The bone marrow from virus positive and virus negative male mice was mixed in different ratios with sexmismatched C57BL/6 female marrow in different ratios to create mixtures resulting in $1 \times 10^{6}$ cells injected. The $\mathrm{Y}$ chromosome positive virus-infected cells were used in mixtures where their component was between $1 \times 10^{5}(10 \%)$ and $1 \times 10^{6}(100 \%)$ of the inoculum. The female recipient C57BL/6 mice were irradiated to $10 \mathrm{~Gy}$. Donor marrow was then injected into irradiated recipient female mice. At 120 days after transplantation, the recipient mice were sacrificed, bone marrow isolated, and DNA extracted. Real time PCR was performed for the detection of $\mathrm{Y}$ chromosome. As shown in Figure 2, Friend virus-infected C57BL/6 bone marrow showed decreased competitive repopulation capacity compared to uninfected marrow. Varying the ratios of uninfected male to female marrow and injection into uninfected C57BL/6 female mice, and marrow harvested at 120 days after injection showed clearly better competitive repopulation (Figure 2). The statistical comparison of the two cell types are in Table I. The Friend virus-infected C57BL/6 marrow sources had reduced repopulation ability compared to the uninfected $\mathrm{C} 57 \mathrm{BL} / 6$ marrow $(p=0.0024)$

The results of the competitive repopulation assay data is presented in Figure 2 as the percent of recipient mice at 120 days that show no detectable male origin Y-chromosome genetic material in the bone marrow of female recipient mice at 120 days. Therefore, the greater number of animals with no detectable male origin marrow in Friend virus-infected donor marrow injected recipients relative to uninfected marrow demonstrates a clear absence of detectable expansion of the hematopoietic stem cell pool in virus-infected C57BL/6 mouse marrow.

TGF- $\beta$ suppression of in vitro colony formation by friend virus-infected marrow. We tested whether TGF- $\beta$ inhibited colony formation in vitro by virus-infected $\mathrm{Fv}-2^{\mathrm{S}}$ compared to $\mathrm{Fv}-2^{\mathrm{r}}$ marrow. There was inhibition of both day 7 and day

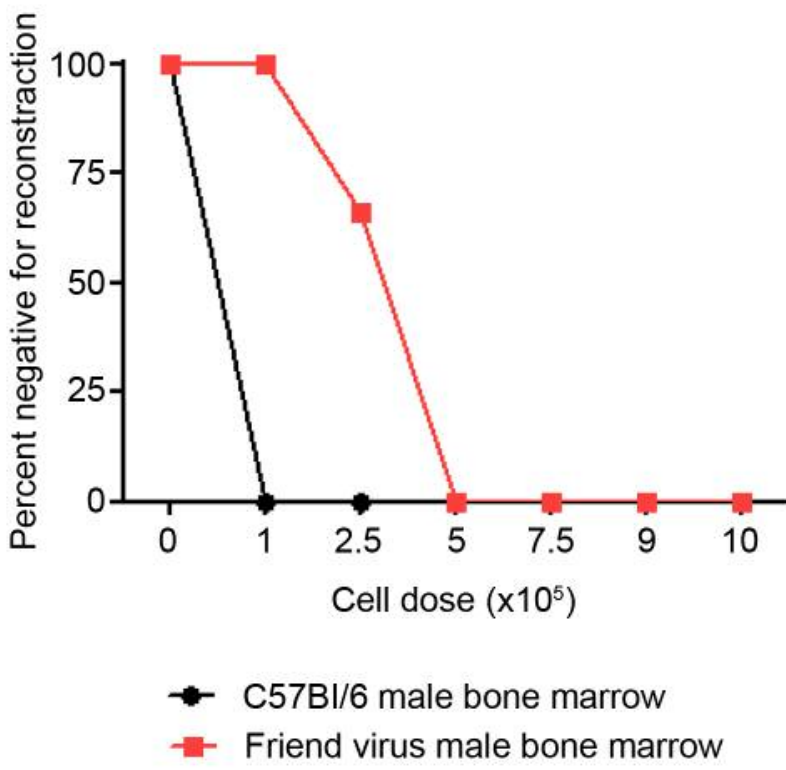

Figure 2. Friend virus infection reduces the competitive repopulation capacity of $F v-2^{r}$ C57BL/6 mouse marrow stem cells. Reduced competitive repopulation capacity of marrow from Friend virus-infected C57BL/6 $\left(F v-2^{r}\right)$ mice was demonstrated. Results are for the day 120 harvest after marrow transplantation of varying ratios of $F V$-infected compared to -uninfected C57BL/6 marrow. Results are presented as described in the "Materials and Methods" section. FV-infected mice had a significantly reduced competitive repopulation capacity $(p=0.0024)$.

14 scored CFU-GEMM colony growth by increasing concentrations of TGF- $\beta$ in both control and Friend virusinfected $\left(\mathrm{Fv}-2^{\mathrm{S}}\right) \mathrm{FVB}$ mouse marrow (Figure $3 \mathrm{~A}$ and $3 \mathrm{~B}$, respectively).

In contrast to virus-infected FVB mouse marrow, $\mathrm{Fv}-2^{\mathrm{r}}$ C57BL/6 virus-infected mice demonstrated decreased numbers of marrow hematopoietic progenitor cells compared to uninfected C57BL/6 mouse marrow. This difference 

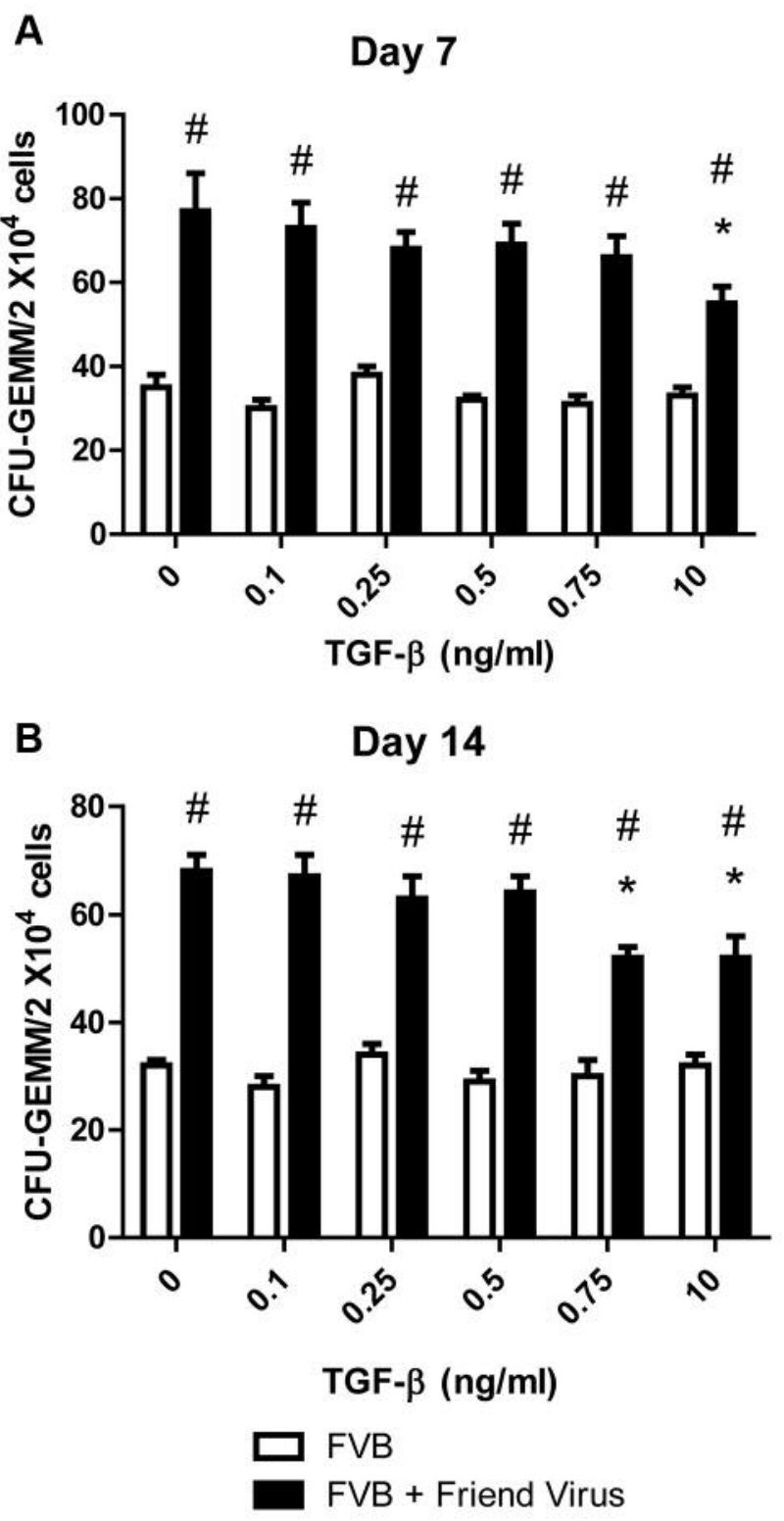

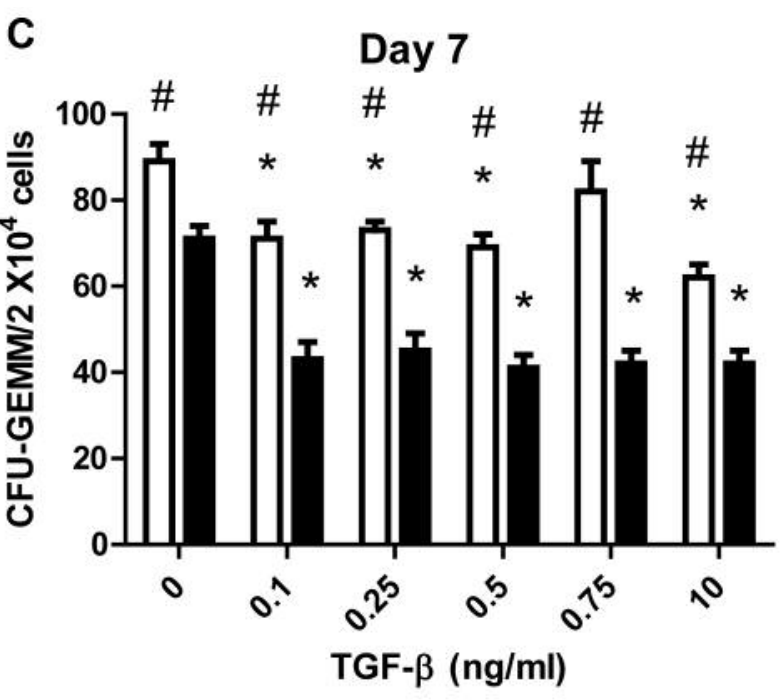

Day 14

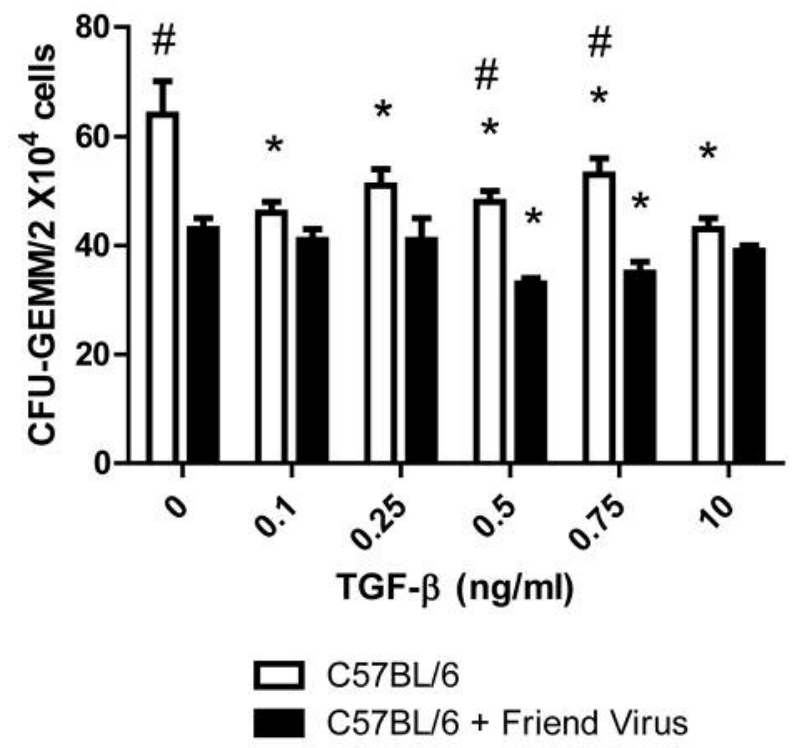

\section{${ }^{*} p<0.05$ compared to $0 \mathrm{ng} / \mathrm{ml}$ TGF $-\beta$ \\ $\# p<0.05$ compared to FVB at same TGF- $\beta$ concentration}

Figure 3. TGF- $\beta$ inhibition of CFU-GEMM from bone marrow isolated from $F v 2^{s}$ and $F v 2^{r}$ mice. Bone marrow was isolated from control as well as Friend virus-infected $F v 2^{s} F v B$ and $F v 2^{r} C 57 B L / 6$ mice and analyzed for the production of day 7 and day 14 CFU-GEMM in the presence of TGF- $\beta$. Bone marrow from Fv2s FvB mice had decreased CFU-GEMM in the presence of TGF- $\beta$ for both Day 7 (Figure 3A) and Day 14 (Figure $3 B$ ). Similar TGF- $\beta$ inhibition of CFU-GEMM was seen at Day 7 (Figure 3C) and Day 14 (Figure 3D) for Fv2r C57BL/6 bone marrow.

between mouse strain hematopoietic assays in vitro has been reported $(4,8,10)$. However, there was also TGF- $\beta$ inhibition of both day 7 (Figure 3C) and day 14 (Figure 3D) scored CFU-GEMM in virus-infected and control C57BL/6 marrow. Thus, TGF- $\beta$ inhibited formation of colonies by committed hematopoietic colony-forming cells in the assays for day 7 and day 14 CFU-GEMM with marrow from both mouse strains. 


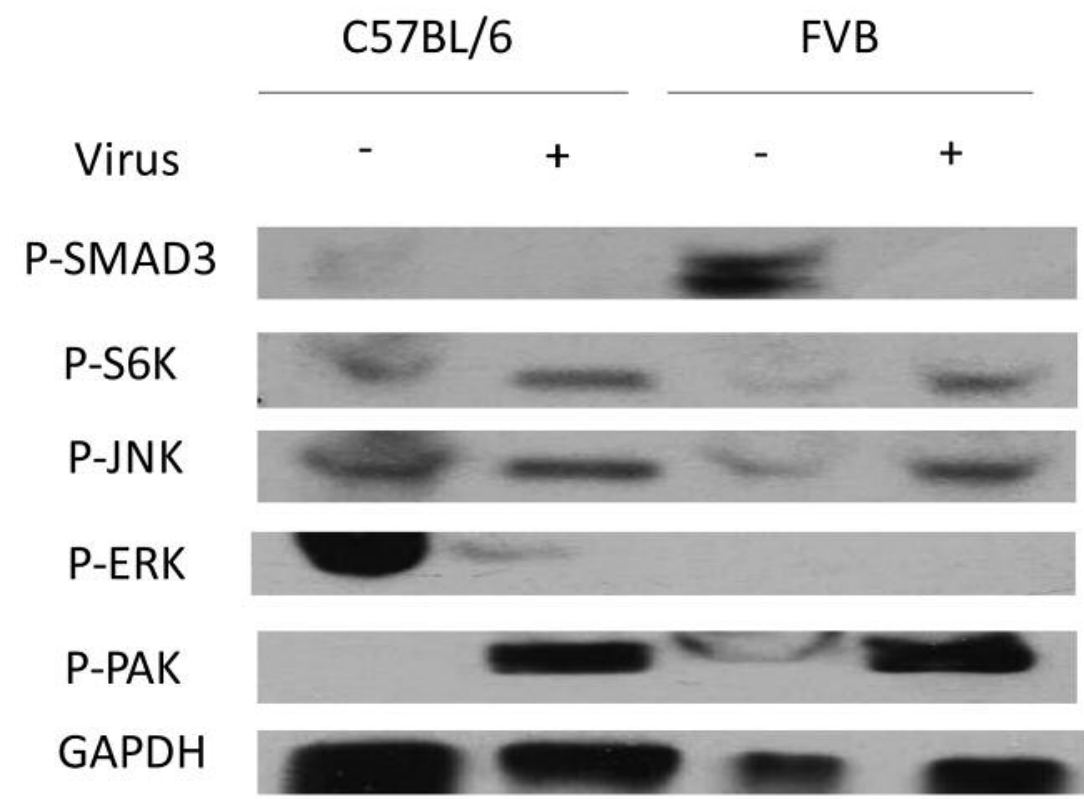

Figure 4. Intact TGF- $\beta$ signaling pathways in $(F V B) F v-2^{s}$ compared to $(C 57 B L / 6) F v-2^{r}$ Friend virus-infected marrow. Friend virus infection suppresses SMAD3 levels in both FVB $\left(F v-2^{s}\right)$ and C57BL/6 $\left(F v-2^{r}\right)$ bone marrow. Western blot of TGF pathway signaling proteins shows decreased SMAD3 and P-ERK but increased levels of expression of P-S6K, P-JNK (in FVB) and p-PAK in both virus-infected mouse marrow.

Suppression of the Smad3-mediated TGF- $\beta$ signaling pathway in friend virus-infected marrow. We assayed the protein markers for five different TGF- $\beta$ signaling pathways in Friend virus-infected mouse marrow of each strain (21). The marrow of both FVB $\left(\mathrm{Fv}-2^{\mathrm{s}}\right)$ and C57BL/6 $\left(\mathrm{Fv}-2^{\mathrm{r}}\right)$, Friend virus-infected mice showed reduced levels of Smad3 and the Smad3 dependent P-ERK pathway (Figure 4). In contrast, there was an up-regulation of other TGF- $\beta$ signaling pathways, including those involving P-PAK, P-S6K and P-JNK in virus-infected marrow.

\section{Discussion}

Erythroleukemia induction by Friend virus in susceptible mouse strains is controlled by the $F v$-2 locus (1). A previous study suggested that erythroleukemogenesis could be separated from the expanded self-renewal capacity of hematopoietic stem cells by using $\mathrm{Fv}-2^{\mathrm{r}}$ mice that are virusinfected, but do not develop fatal splenomegaly and leukemia (2). The Friend virus is known to expand the pool size of non-malignant multipotential and differentiated colony-forming cells measured in vitro (3). The assay for spleen focus formation by Friend virus (SFFV) in $\mathrm{Fv}_{-} 2^{\mathrm{s}}$ marrow (3-9) was used to quantitate virus titer in prior studies. The prior study of true stem cells in $\mathrm{Fv}-2^{\mathrm{r}}$ mice used the serial transplantation method (2) rather than the competitive repopulation assay (15). In the serial transfer assay, C57BL/6 mice were injected with the Friend virus, their marrow harvested at 12 days and injected intravenously into a second generation of lethally irradiated syngeneic C57BL/6 mice (2). Successive generations of marrow transfer every 12 days led to an increased number of serial transfers that significantly exceeded the number observed when uninfected marrow was used (2). These experiments suggested that the expansion of hematopoietic stem cell numbers by Friend virus could be separated from erythroleukemogenesis by using difference at the $F v$-2 locus.

The serial transfer assay has been questioned as to its true reflection of numbers of multilineage hematopoietic stem cells in the bone marrow. In contrast, the competitive repopulation assay (15) in which a single generation of lethally irradiated recipient mice is injected with varying ratios of each of two bone marrow sources use a difference in gender in the assay for Y-chromosome in peripheral blood and marrow. At 120 days after transplantation of these combined mixed marrow sources into lethally irradiated recipient mice the data has been shown to be more representative of a relative abundance of true hematopoietic stem cells. The competitive repopulation assay is commonly used to accurately quantitate expansion of true hematopoietic stem cells. The logic of this technique is that 120 days is necessary to deplete lethally irradiated recipients of the function of committed hematopoietic progenitor cells, including those with capacity to differentiate to granulocyte-macrophage, multilineage erythroid/ megakaryocyte/macrophage/neutrophil, as well as lympho-hematopoietic progenitor cells, but not primitive multipotential stem cells. 
In the present studies, we tested whether competitive repopulation assay supported a previous study using the serial transfer assay, to confirm true hematopoietic stem cell numbers had increased in Friend virus-infected $\mathrm{Fv}-2^{\mathrm{r}}$ C57BL/6 mice. If the competitive repopulation assay had confirmed the prior serial transfer assay (2), this result would suggest that the Friend virus had expanded stem cell numbers under conditions, in which the Friend virus erythroleukemia did not occur. Such information might have motivated us to carry out experiments to determine the gene or genes in the Friend virus that had induced stem cell expansion in the absence of erythroleukemogenesis.

The present studies did not provide evidence for expansion of true multipotent hematopoietic stem cells in $\mathrm{Fv}-2^{\mathrm{r}} \mathrm{C} 57 \mathrm{BL} / 6$ mice that were infected with Friend virus. Therefore, these results suggest that the prior use of serial transfer assay (3) may have been measuring committed progenitor cell expansion rather than true stem cells. The present data also suggest that the significant increase in production of hematopoietic cells and increased longevity of hematopoiesis in long-term bone marrow cultures (LTBMCs) derived from Friend virus-infected C57BL/6 mice (4). The longevity of Friend virus-infected marrow in LTBMCs from C57BL/6 mice may have reflected the in vitro culture system in which high levels of added 17hydroxy corticosteroid and absence of immunoregulatory cells represent artificial growth conditions for bone marrow (3-8). Furthermore, the indirect effect on hematopoietic cells of the hematopoietic microenvironment may be a critical factor reported then and still of relevance now in understanding marrow committed stem cells $(8,16-17)$. Finally, the lack of use of a clonal Friend virus in prior studies $(3,4,8,16-17)$ may have introduced confounding variables, not testable in the present studies.

Like Friend virus infection of marrow in vitro (4), inhibition of TGF- $\beta$ signaling in Smad3-/- bone marrow also shows a significantly increased duration of hematopoiesis in long-term cultures (13) compared to the longevity of hematopoiesis in wild-type mouse bone marrow stem cells, which have intact TGF- $\beta$ signaling (13). A recent publication showed that TGF- $\beta$ hyper-responsiveness of hematopoietic stem cells from Fanconi anemia $\left(\right.$ Fancd $\left.2^{-/-}\right)$mice exhausts the hematopoietic stem cell compartment, decreases competitive repopulation capacity of stem cells and produces marrow failure (12). Whether Friend virus acted by blocking TGF- $\beta$ signaling and resulted in expansion of marrow stem cell self-renewal (2) has not been previously investigated. We found that TGF- $\beta$ suppressed CFU-GM formation in vitro by both virus-infected and uninfected $\mathrm{FvB}$ and C57BL/6 marrow in vitro. Furthermore, the suppression occurred despite down-regulation of 2 of the 5 TGF- $\beta$ signaling pathways (Smad3 and P-ERK) in virus-infected marrow of both mouse strains.
The present results establish that the erythroleukemogenic Friend virus does not detectably expand true normal marrow stem cells in $\mathrm{Fv}-2^{\mathrm{r}}$ mice using the competitive repopulation assay.

\section{Acknowledgements}

The present study was supported by Grant from the NIH/NIAID U19-A168021 and the Fanconi Anemia Research Fund. This project used the UPCI animal facility that is supported in part by award P30CA047904. The Authors wish to thank Drs. Sandra Ruscetti and Frank Ruscetti for helpful discussion and encouragement.

\section{References}

1 Persons DA, Paulson RF, Loyd MR, Herley MT, Bodner SM, Bernstein A, Correll PH and Ney PA: Fv2 encodes a truncated form of the Stk receptor tyrosine kinase. Nature Genetics 23: 159-169, 1999.

2 Eckner RJ, Hettrick KL, Greenberger JS and Bennett M: Extended self-renewal capacity of pluripotential hematopoietic stem cells: Association with persistent Friend spleen focus forming virus. Cell 31: 731-738, 1982.

3 Greenberger JS, Hoffman N, Lieberman M, Botnick LE, Sakakeeny MA and Eckner RJ: Pool size or pluripotential hematopoietic stem cells increased in continuous bone marrow culture by Friend spleen focus forming virus. J Nat Canc Inst 70: 323-331, 1983.

4 Greenberger JS, Daugherty C, Sakakeeny MA, Braun J, Pierce JH, Eckner RJ and Fitzgerald TJ: Friend virus-infected long-term bone marrow cultures produce colony stimulating factordependent and independent granulocyte-macrophage progenitor cells for over four years in vitro. Leukemia Res 11: 51-61, 1987.

5 Greenberger JS, Gans PJ, Davisson PB and Moloney WC: In vitro induction of continuous acute promyelocytic leukemia cell lines in long-term bone marrow cultures by Friend or Abelson leukemia virus. Blood 53: 987-1001, 1979.

6 Greenberger JS, Newburger PE, Lipton JM, Moloney WC, Sakakeeney MA and, Jackson PL: Viral and cellular requirements for Friend virus granulocytic leukemogenesis in long-term marrow cultures. J Nat Canc Inst 64: 867-878, 1980.

7 Greenberger JS, Eckner RJ, Ostertag W, Colletta G, Boschetti S, Nagasawa H, Karpas A, Weichselbaum RR and Moloney WC: Release of spleen focus forming virus (SFFV) in differentiation inducible granulocytic leukemia cell lines transformed in vitro by Friend leukemia virus. Virol 105: 425-436, 1980.

8 Greenberger JS, Eckner RJ, Sakakeeny M and Cohen G: Role of stromal and hematopoietic stem cells in Friend spleen focus forming virus effects in continuous bone marrow culture. Leukemia Res 7: 621-636, 1983.

9 Kluge NK, Ostertag W, Fusco A, Pennie S and Greenberger JS: Multipotential hematopoietic cell lines isolated from stem cell cultures infected with Friend virus complex (MuLV + F-SFFV) show presence of MuLV but not F-SFFV. Leuk Res 10: 187-193, 1986.

10 Sakakeeny MA and Greenberger JS: Granulopoiesis longevity in continuous bone marrow cultures and factor dependent cell line generation: Significant variation among 28 inbred mouse strains and outbred stocks. J Nat Canc Inst 68: 305-317, 1982. 
11 Ohta M, Greenberger JS, Anklesaria P, Bassols A and Massague $\mathrm{J}$ : Two forms of transforming growth factor- $\beta$ distinguished by multipotential haematopoietic progenitor cells. Nature 329: 539$541,1987$.

12 Zhang H, Kozono DE, O'Connor KW, Vidal-Cardenas S, Rousseau A, Hamilton A, Moreau L, Gaudiano EF, Greenberger J, Bagby G Soulier J, Grompe M, Parmar K and D'Andrea AD: TGF- $\beta$ inhibition rescues hematopoietic stem cell defects and bone marrow failure in Fanconi anemia. Cell Stem Cell 18: 114, 2016.

13 Epperly MW, Cao S, Goff J, Shields D, Zhou S, Glowacki J and Greenberger JS: Increased longevity of hematopoiesis in continuous bone marrow cultures and adipocytogenesis in marrow stromal cells derived from SMAD3-/- mice. Exp Hemat 33: 353-362, 2005.

14 Epperly MW, Goff J, Zhang X, Shields D, Wang H, Shen H, Franicola D, Bahnson A, Greenberger EE and Greenberger JS: Increased radioresistance, G2M checkpoint inhibition, and impaired migratory capacity of bone marrow stromal cell lines derived from SMAD3-/- mice. Radiat Res 165: 671-677, 2006.

15 Garaycoechea JI, Crossan GP, Langevin F, Daly M, Arends MJ and Patel KJ: Genotoxic consequences of endogenous aldehydes on mouse haematopoietic stem cell function. Nature 489: 571578,2012

16 Longo VD and Cortellino S: Enhancing stem cell transplantation with "nutri-technology". Cell Stem Cell 19: 681-682, 2016.

17 Taya Y, Ota Y, Wilkinson AC, Kanazawa A, Watarai H, Kasai $\mathrm{M}$, Nakauchi $\mathrm{H}$ and Yamazaki S: Depleting dietary valine permits nonmyeloablative mouse hematopoietic stem cell transplantation. Science 354: 1152-1154, 2016.

18 Till JE and McCulloch EA: A direct measurement of the radiation sensitivity of normal mouse bone marrow. Radiat Res 14: 213-220, 1961
19 Greenberger JS: Long-term hematopoietic cultures. In: "Methods in Hematology", Golde D, Ed., Churchill Livingston, New York, pp. 203-243, 1984.

20 Epperly MW, Franicola D, Dixon T, Cao S, Zhang X, Shields D, Wang $\mathrm{H}$, Wipf $\mathrm{P}$ and Greenberger JS: Induction of TGF- $\beta$ by irradiation or chemotherapy in Fanconi Anemia (FA) mouse bone marrow is modulated by small molecule radiation mitigators JP4-039 and MMS350. In Vivo 31: 159-168, 2017.

21 Zhang YE: Non-smad pathways in TGF- $\beta$ signaling. Cell Res 19: 128-139, 2009.

$22 \mathrm{Hu} \mathrm{Y}$ and Smyth GK: ELDA: extreme limiting dilution analysis for comparing depleted and enriched populations in stem cell and other assays. J Immunol Methods 347(1-2): 70-78, 2009.

23 Zhang J, Randall MS, Loyd MR, Li W, Schweers RL, Persons DA, Rehg JE, Noguchi CT, Ihle JN and Nev PA: Role of erythropoietin receptor signaling in Friend virus-induced erythroblastosis and polycythemia. Blood 107(1): 73-78, 2006.

24 He S, Ni S, Hegde S, Wang X, Sharda DR, August A, Paulson RF and Hankey PA: Activation of the N-terminally truncated form of the Stk receptor tyrosine kinase Sf-Stk by Friend virusencoded gp55 is mediated by cysteine residues in the ecotropic domain of gp55 and the extracellular domain of Sf-Stk. J Virol 84(5): 2223-2235, 2010. 